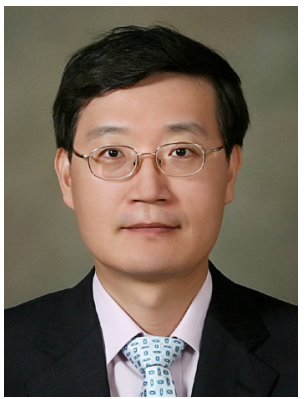

Received: December 10, 2019

Revised: December 12, 2019

Accepted: December 13, 2019

Corresponding author:

Joon Hyuk Choi

Department of Pathology,

Yeungnam University College of

Medicine, 170 Hyeonchung-ro,

Namgu, Daegu 42415, Korea

Tel: +82-53-640-6754

Fax: +82-53-656-1429

E-mail: joonhyukchoi@ynu.ac.kr

\section{First step to international journal by indexing PMC and DOAJ}

\section{Joon Hyuk Choi}

\author{
Editor-in-Chief \\ Department of Pathology, Yeungnam University College of Medicine, Daegu, Korea
}

The Yeungnam University Journal of Medicine (YUJM) was first published in December 1984 as the official journal of the Yeungnam University College of Medicine. It is an international, peer-reviewed, and open access journal. The aim of YUJM is to communicate new medical information to the medical personnel and facilitate the development of medicine through propagation of medical knowledge by publishing high quality evidence-based articles. It has been published in English since 2018.

YUJM has been indexed in both the Directory of Open Access Journals (DOAJ; June 2019) and PubMed Central (PMC; October 2019). It has been available for journal article search through PubMed since the publication of volume 35, issue 1, 2018. The significance of YUJM being indexed in DOAJ and PMC is as follows: firstly, it has advanced to an international-level journal; secondly, it can be easily searched in PubMed; and lastly, journal citations will increase because they are available online to be read and used readily. To promote YUJM to SCOPUS and SCIE-indexed journals, the efforts toward maintaining the high scientific standard of the journal need to be continued; additionally, there is a need to increase the critical mass and standard of content.

Finally, I would like to express my sincere thanks to the former editor-in-chiefs, members of the editorial board, reviewers, manuscript editors, and publishers for their utmost devotion to the success of YUJM. In particular, I deeply appreciate all authors of the articles for their support and contribution. I hope that the readers and researchers will share their valuable thoughts and experiences, and recent information in the field of medical science.

\section{Acknowledgments}

\section{Conflicts of interest}

No potential conflict of interest relevant to this article was reported.

\section{ORCID}

Joon Hyuk Choi, https://orcid.org/0000-0002-8638-0360 